\title{
English as the official working language of the Association of Southeast Asian Nations (ASEAN): Features and strategies
}

\author{
ANDY KIRKPATRICK
}

English as a lingua franca: a specific example

\section{Introduction: English in ASEAN}

The Bangkok Declaration of 8 August 1967 heralded the formation of the Association of Southeast Asian Nations (ASEAN). While today all ten nations of Southeast Asia are members, the number of founder member states was only five: Indonesia; Malaysia; the Philippines; Singapore; and Thailand. Brunei joined in 1984, Vietnam in 1995, Laos and Burma (Myanmar) in 1997 and finally, Cambodia, in 1999. In what may strike members of the European Union as particularly remarkable, the use of languages was not stipulated in the Bangkok Declaration. English has always been the sole official and working language of the group. In her study of the process behind this adoption of English as the only official language, Okudaira interviewed a number of key ASEAN figures and received answers, of which these are representative:

'the idea of English as the common language came out automatically' ... 'there has been no regulation for the use of English but it has been used in all the actual situations' ... 'we took it for granted' (1999:95-6)

There have only been two attempts to introduce other working languages and both failed (Okudaira, 1999). The first attempt took place when Vietnam's membership was under discussion and the Vietnamese asked whether French might be adopted. The second attempt occurred in 1997 at the meeting of the ASEAN Committee on Culture and Information when the Malaysian Minister for Information sug- gested the adoption of Malay as a second working language. The suggestion was not even discussed.

The de facto adoption of English as the sole working language of ASEAN is about to be formalized. At the ASEAN Summit in November 2007, the ASEAN Charter was introduced. Article 34 'Working Language of the ASEAN' reads: 'The working language of ASEAN shall be English'. This is the only mention of working or official languages in the entire charter. To become legally binding, all ten member states must ratify the Charter before the next ASEAN Summit, to be held in December 2008 and to date, Brunei, Laos, Malaysia and Singapore have done so. There is no indication that any of

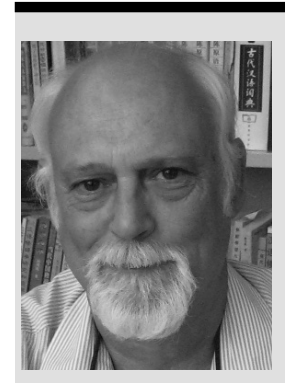
ANDY KIRKPATRICK is
Professor of English at the
Hong Kong Institute of
Education and Director of the
Institute's Research Centre for
Language Education in
Multilingual Societies. He has
previously taught in Australia,
Burma, China, England,
Singapore and Taiwan. He is author of 'World Englishes: Implications for International Communication and English Language Teaching' (CUP, 2007). He is currently World Englishes'. He has also published wid
aspects of Chinese discourse and rhetoric. 
the member states will refuse to ratify so it would appear that, by the end of the year, the position of the English as the sole working language of ASEAN will be legally enshrined.

ASEAN provides a particularly interesting site for the study of English as a lingua franca because the member states, following Kachru's 'circles' classification (1985), fall into distinct categories. Brunei, Malaysia, the Philippines and Singapore can be classified as 'outer circle' countries, where, because of their colonial past, English continues to play a major role and where it is possible to talk about the Brunei, Filipino, Malaysian and Singaporean varieties of English. Yet, the history of English in these countries since their independence has been anything but similar. For example, Malaysia's National Language Act of 1967 mandated the gradual shift from English to Malay as the medium of instruction in all government schools and universities. As this act was passed in the same year that Malaysia became a founding member state of ASEAN, this makes it all the more surprising that English was tacitly accepted as the sole working language. Malaysia's policy has since shifted back to the use of English so that it is now used as the medium of instruction for maths and science subjects in schools.

While Burma seems to fit into the 'outer circle' category in the sense that it was once a British colony and where English played a major role, the inward-looking zenophobic policies initiated by U Ne Win from 1962 led to the marginalization of English, a marginalization that there has been some attempt to reverse in recent years, but with little success. Indonesia is a different case, representing a hugely diverse range of languages and cultures. After freedom from first the Dutch and then the Japanese, Indonesia has sought to use a local language, Bahasa Melayu (Malay), to act as a national lingua franca. In this, it has been remarkably successful, so that the great majority of Indonesians are now able to communicate through what is called Bahasa Indonesia. English is the second language of the educated urban elite and is also the first foreign language taught in schools, but with limited success (Dardjowidjojo, 2000). In Thailand, the only country within ASEAN that has never been colonized, English is also the first second language. More recently, the countries that made up the French colony of Indo-China, namely Cambodia, Laos and Vietnam have become member states. These countries have witnessed an urgent shift from French to English, but levels of English even among the elite - particularly in Laos and Cambodia - remain comparatively low. English in these countries is therefore at different stages of development (Bolton, 2002).

\section{Lingua franca: form or function?}

This means that English is used as a lingua franca by people ranging from those who speak a local variety of English such as Malaysian to those whose proficiency in English remains relatively low. There has recently been some debate, concerning definitions of English as lingua franca and the extent to which it refers to a single variety of English (Seidlhofer, 2004; Jenkins, 2007; Prodromou, 2007b). It is important to clarify here, therefore, that ASEAN ELF is not a single variety. It is perhaps helpful to see lingua franca more as a functional term rather than a linguistic one. In the ASEAN context described above, it is clear that the English used by speakers is likely to be characterized by variation and variety. This gives rise to two related questions. First, 'How do people who speak different varieties of English and people whose level of English may be low communicate with each other using English as a lingua franca? Second, 'Notwithstanding the different varieties being used, are there any shared or distinctive linguistic features in the Englishes used by these people?'

In the remainder of this article, I shall first describe a small selection of linguistic features - phonological and syntactic - that, are shared by speakers of these different varieties ${ }^{1}$ and then consider some of the communicative strategies - including the lack of use of 'local' lexis - the speakers adopt to ensure that their communication is successful. The data comes from twenty English teachers, two from each country in ASEAN, recorded in conversation in groups of three for four. As English teachers, their proficiency levels are, in the main very high - many are expert users (see Rampton, 1990) - although there are some - tellingly from Laos and Cambodia - whose level of proficiency is markedly lower than the others.

\section{Some shared phonological features}

Perhaps the most striking phonological feature that is shared by these speakers is their 
tendency to use syllable-timing caused, at least in part, by the avoidance of reduced vowels. This may well be because so many of the speakers' first languages have a tendency to syllable timing. In any event it is a characteristic of almost all the speakers in the data. It is also interesting to note that this feature is also characteristic of many other new varieties of English (cf. Gramley \& Patzold, 2004).

Here are just two of many examples of the use of full vowels in unstressed syllables (see Deterding \& Kirkpatrick, 2006:395-401, for these and further examples).

1 It's OFficially launched (male Indonesian)

2 When I first came TO Singapore (male Thai)

Speakers in the data also regularly stress pronouns. The first example is of a stressed subject pronoun and the second of a stressed object pronoun.

3 And HE has been in Singapore three times (female Burmese)

4 I grew up with a lot of languages around ME (female Bruneian)

Heavy end stress, as illustrated in the examples below, is also common.

5 we have the government schools and the private SCHOOLS (female Bruneian)

6 and very few people speak ENGLISH (male Cambodian)

Turning to segmental features, the dental fricatives are regularly replaced by [t] and [d]. This is not surprising, as speakers of many different varieties of English - including some native speaker varieties - also replace these with other sounds. Some London speakers actually replace them with [f] and [v] (Wells, 1982:328), but this is not found in the ASEAN data, although it is found in the speech of Hong Kong English (Hung, 2000; Deterding, Wong \& Kirkpatrick, 2008).

The diphthongs /ei/ and /ə↔Y/ are regularly replaced by monophthongs, as in the examples 'another [ple's]' for 'another place' and 'can [go']' for 'can go'. As will be illustrated in the discussion of syntax, there are also frequent occurrences where final consonant clusters are simplified, but this occurs in many varieties of English, including native-speaker varieties (Fabricius, 2002).

What is interesting is that none of these features appear to cause any problems of communication among these speakers. Indeed, there are very few instances in the data where com- munication breaks down, and this appears to be caused by the participants whose level of English is comparatively low either pronouncing words in such a way that the hearers cannot make them out, or by themselves not being able to follow the conversation. An example of the first is presented below. This conversation is between a Malaysian male [M], a Filipina [F] and a Laotian male [L]. It is the Laotian's pronunciation of the word 'hole' that causes the problem (see Kirkpatrick, 2007b for this and further examples).

$7 \mathrm{~L}$ : you know at the time that ehm tsunami occurs they there were some problem in my country

M: what problem?

L: yeah we've some problem we have big hornz in some areas

M: horns? Sorry

L: horn you hornt

F: hornt?

L: yeah big horn

M: (laugh) sorry

F: what's a horn?

L: (spells out) H...O...L...E something like this

$\mathrm{M}$ : holes oh you mean hole in the ground

L: yeah

F: ah hole.

So, when the pronunciation is so far from a known standard pronunciation and when the word cannot be retrieved from the context, breakdown occurs. It is, of course, very difficult to determine how far from a known standard a pronunciation has to be before it comes unintelligible. Context often allows participants to understand what is being said. In the next example, the Vietnamese speaker [V] pronounces the past tense form of teach as 'TORCH', but it is not clear whether this causes problems or not or whether the other participants, a Thai $[\mathrm{T}]$ and a Burmese [B], are adopting the 'let it pass strategy' (Firth, 1996:243).

$8 \mathrm{~V}:$...those students will be torch all the basis rules

$\mathrm{T}: \mathrm{mm}$

V: like I mean this, for the er for the sub- for the grammar subject itself, it's not for interpreter skills

B: $\mathrm{mmm}$

When an Indonesian participant [I] uses this pronunciation of 'taught' it obviously presents no problems, not least because it occurs immediately after the Singaporean participant [S] has anticipated what the Indonesian is going to 
say and provided 'taught'. Interestingly, however, the Indonesian still says 'torch'.

9 I...we are working on the way er what's I the curriculum yeah and on the way how English er

S: is to be taught

I: is to be torch

Examples of where breakdown is cause by a participant being unable to follow the conversation are provided in the section on communicative strategies. The next section provides selected examples of syntactic features.

\section{Syntactic features}

In terms of the use of tense forms, which is the main focus of this section, there is remarkably little use of 'non-standard' forms. ${ }^{2}$ Table 1 shows the overall use of the tense forms in the speech of the twenty subjects along with the number (in brackets) of non standard forms.

Table 1 shows that the Present Simple Tense is by far the most commonly used tense, fol-

\section{Table 1: Overall totals and totals by 'tense' with number of non-standard forms}

\begin{tabular}{lrc}
\hline 'Tenses' & $\begin{array}{r}\text { Tokens } \\
\text { Total }\end{array}$ & $\begin{array}{c}\text { Non-standard } \\
\text { forms }\end{array}$ \\
\hline Present Simple & 1831 & 107 \\
\hline Past Simple & 321 & 33 \\
\hline Modals & 228 & 1 \\
\hline Present Passive & 47 & 4 \\
\hline Present Perfect & 43 & 4 \\
\hline Present Continuous & 26 & 3 \\
\hline Past Passive & 16 & 2 \\
\hline Present Perfect Continuous & 10 & 1 \\
\hline Present Perfect Passive & 4 & - \\
\hline Imperative & 5 & - \\
\hline Infinitive Passive & 4 & 1 \\
\hline Past Continuous & 3 & 1 \\
\hline Past Perfect & 3 & - \\
\hline 'Going to' & 2 & - \\
\hline Please + Vb & 2 & - \\
\hline Present Continuous Passive & 1 & - \\
\hline Other & 5 & - \\
\hline & & \\
\hline
\end{tabular}

lowed by the Past Simple. The table also shows that the use of certain tenses is very rare. Perhaps most interestingly, however, is the relatively low number of non-standard forms. These are discussed in more detail below, but they comprise, in the main, concord and nonmarking.

Table 2 shows which of the speakers uses the non-standard forms. The first languages of the two Singaporean participants and the single Malaysian are also identified. Thus, in this table, SingaporeM and SingaporeP refer to the Singaporean Malay and Singaporean Indian (Punjabi) participants respectively. MalaysianM and MalaysianC refer to the Malay Malaysian and the Malaysian Chinese respectively.

Table 2 shows that the majority of participants use very few non-standard forms. The only participants for whom non-standard forms constitute more than 6 per cent are one of the Indonesians, both Cambodians and both Laotians. It is difficult to find a scientifically satisfactory way of determining between an expert user of English and a learner, but the four whose use of non-standard forms exceeds 15

Table 2: Tense use and non-standard forms by participant

\begin{tabular}{lrrc|} 
Participant & Tokens & 'Non & \%age of \\
-standard' & non-standard
\end{tabular}


per cent might be classified as learners of English, especially when the types of non-standard forms they use are considered. The fact that all four also come from Laos and Cambodia, countries where, as mentioned earlier, English has only relatively recently become the second language, might also support this. An example is provided in excerpt (10), which shows one of the Laotian speakers (L1) in conversation with the Singaporean Punjabi (SP) and Burmese (B).

10 L1: ehm last NAI we went there by walking

SP: eh huh

L1: I enjoy walking [yeah

S: you] mean all the way from [here

B: yes yes

L1: yeah]

SP: oh ok

L1: some of my friend hurt his feet

SP: oh ok

L1: (laugh) he can't $\{\mathrm{M}$ : yes $\}$ walk and he is just stand and sit (quiet laugh)

While L1's use of concord is non-standard ('some of my friend hurt his feet') she also uses forms that cannot be explained by the nonmarking of present or past tenses. For example, in the final line of this extract she says '... he is just stand and sit'. She thus chooses to use the third person of the copula alongside two bare infinitives, where we might reasonably expect 'he just stood and sat'. In the next example, she is explaining that she is on her first overseas trip and that is why she just follows along.

11 SP: he's your tour guide] (laugh)

B: politically our our leader (general laughter) and tour guide

SP: eh hm

$\mathrm{B}$ : and so

SP: please begin

L1: er for me er I just follow her (laugh) because I (laugh) don't know anything it's my first time to er go in on another country

SP: oh ok so what so [what was your

L1: it's hardly] for me to er doing everything

SP: what was your first impression?

L1: yeah

SP: when you came to Singapore

L1: I can't get ?or new meaning? from Singapore yet

Some half-way thought this extract, L2 says 'it's hardly for me to er doing anything'. She uses this form 'it's hardly to' in two other contexts and here also combines an infinitive 'to' with the gerund form 'doing'.
These non-standard forms contrast strikingly with those used by more fluent speakers. In example (12) below, the Indonesian (I2) uses a number of non-standard forms, but these are almost all accounted for by the nonmarking of the past tense.

12 I2: I waited for the official who PIK me up $\mathrm{OK}$ and then I tried to look for the official but because ere $r$ the plane you know landed early so early so the official hadn't come yet

B2: what a pity

I2: I had to stay in the airport and then did nothing just sit and I check the placard of RELC ok and I couldn't see that's why I just sit and take a rest...what about you what time

$\mathrm{C} 2$ : how long have you waits for them?

(Kirkpatrick 2007a:160)

In this extract, $\mathrm{I} 2$ marks the past tense in her first turn with 'waited', 'tried' and 'landed' (it is not clear what she meant by PIK here, but possibly something like 'who was to pick me up'). She also marks a past perfect form (hadn't come'). In her second turn, however, after marking the initial past tense forms ('had' and 'did') she does not mark the past tense on several verbs that occur later in the utterance ('sit', 'check', 'sit' and 'take').

This shows that, while she clearly knows the standard rule and is able to apply it, she often does not do so. It is possible that the non-marking of 'check' may have a phonological cause (checked is difficult to say and non-marking here would be common in the speech of native speakers), but the non-marking of 'sit' and 'take' cannot be explained in this way. It seems more likely that this is a case where the time has already been established and marking for it appears redundant. This type of non-standard use is common and I argue that it is not necessarily the sign of a learner of English, but can be part of the performance variety of expert users of English, especially of those whose first languages do not mark for tense (as is the case with Malay, this speaker's first language). The non-marking of past tense forms in this way may also be part of the historical shift to syntactic regularization and simplification, manifestations of which are a tendency for irregular forms to become regular (from 'wrought' to 'worked', from 'slew' to 'slayed', for example) along, with the related phenomenon of new verbs into the language always adopting regular past tense forms) (Lieberman et al., 2007), 
and a historical tendency for the gradual simplification of verbal morphology so that the highly complex system of verbal conjugation that operated upon Old English has become reduced, in the context of the simple present tense, to the single marked form of the third person singular '-s', for example. While this ' $-\mathrm{s}$ ' represents the standard form, there is considerable variation in its use in British dialects (Ihalainen, 1994:228). This 'instability' of use has led Mesthrie to suggest that it is not surprising to find that it 'is quite frequently absent in L2 varieties' (2004:1135).

In other words, by not marking these tense forms, the Indonesian speaker may be assuming they are simply not needed in the context, as they are redundant and she may also be, unwittingly of course, anticipating syntactic change. This use of non-standard forms is common in the data and it does not necessarily signal a learner. The use of non-standard forms of the type used by the Laotian speaker, however, cannot be explained by redundancy and may signal a learner. The Cambodian speaker in example (12) might also fit this category, as she asks 'how long have you waits for them?' Far from non-marking because of redundancy, this speaker has added the $-\mathrm{s}$; inflection. It is not needed either for concord or for tense marking. This, together with the number of non-standard forms she uses, also suggests a learner.

To sum up this section, there is relatively little syntactic variation in the marking of verb forms in the speech of these ASEAN speakers, with the exception of those who could be classified as learners. A major source of non-standard forms among the majority of these speakers comprises the non-marking of third person present simple and past tense forms, and this non-marking can be explained by the redundancy of these forms in specific contexts. Finally, the relative lack of the use of complex tense forms needs to be noted. More data from more contexts is needed, but these findings support Mesthrie's conclusion that complex tenses tend to be avoided in East African varieties of English (2004). They also support Meierkord (2004), who found that 94 per cent of the utterances of the outer-circle speakers in her data were regular. She was surprised by this, as 'it contradicts the assumption that speakers would carry the characteristics of their nativised varieties into the English lingua franca interactions' (2004:119).

Therefore, despite some of the interactants speaking different varieties of English and some having different levels of proficiency in English, paradoxically, there is actually less variation than might have been expected. Indeed, there is far greater variation both among and between established and new varieties of English than there is here (Kirkpatrick, 2007a). A useful list of non-standard features of varieties of English is provided in Hickey (2004:586-614). One possible explanation of this relative lack of variation is that, by definition, the speakers in these interactions are focusing on communication and this may lead them to ensure they do not use features, words and idioms which they feel might not be understood by other participants.

The next section therefore describes a selection of communicative strategies adopted by these speakers. These include the non-use of local idioms, as this represents a strategy to ensure mutual cross-cultural understanding.

\section{Communicative strategies}

A detailed list of ten listener strategies and five speaker strategies is provided in Kirkpatrick (2007b). Here three strategies are considered, including the use of paraphrase and the let it pass' strategy. The first strategy to be considered is the speakers' non-use of local idioms or lexis. Seidlhofer (2001:16) has argued that what she calls 'unilateral idomaticity' is likely to cause cross-cultural understanding, as speakers will not be familiar with the idioms used in other cultures. It is true that the use of culturally specific idioms is a striking feature of local varieties of English. For example, the Chinese writer, Ha Jin uses memorable expressions derived directly from Chinese in his writing in English. Examples include a 'flowered pillowcase' to describe someone who may look attractive, but has no depth, and 'they breath through the same nostril' to describe people who are always in agreement with each other. Honna (2006) has argued that this adoption of the local idiom into the local variety of English gives the local variety its distinct flavour, and such creativity and distinctiveness should be encouraged. And the Japanese expression 'a son will chew on his parents' shins' is a visually arresting image of a son who remains financially dependent on his parents well into adulthood. Prodromou (2007a:37) cites the Serbian expression 'one should not mix frogs with grandmothers' as being likely to 
cause puzzled stares when used as an English expression. But, as Prodromou points out, the use of local idioms is rare in lingua franca usage and this is supported in the data. In the ASEAN data there is no use of local idiom here at all. This may be because the speakers are all educated multilinguals who are consciously aware that the use of language or variety specific lexis and idiom would be likely to cause misunderstanding and they therefore do not use them. When multilinguals of the same linguistic backgrounds communicate with each other, the use of frequent code mixing is common (Li, 2002; McLellan \& David, 2007), as all parties share the same linguistic resources. When, however, the speakers come from different linguistic backgrounds and are using English as a lingua franca, code-mixing ceases. There is only one occasion in the data when a speaker uses a lexical item from his L1. This is when the Singaporean Malaysian speaker uses the Malay word 'rojak' (literally 'mixed' and which refers to certain type of Indonesian salad) to refer to the colloquial English of Singapore. This will be understood by the Indonesian participant but not by the third member of the group, a Cambodian. For a moment then, the Indonesian and Singaporean speakers appear to forget that the Cambodian will not understand them. Even so, their discussion allows the Cambodian to come to some understanding of the term.

13 SM: ....all the English and Singlish are all mixed together like rojak

I: oh like rojak like that

SM: yes you know rojak right

I: yes, it's fruits mixed

SM: all up together

(Kirkpatrick, 2007a: 168)

Moving from the strategy of the avoidance of localised lexis and idiom, other communicative strategies adopted by the speakers lend support to Firth's finding that speakers in lingua franca conversation often adopt a 'let it pass' strategy (1996:243). Example (8) above, reproduced here, illustrates this.

$14 \mathrm{~V}$ : ...those students will be TORCH all the basis rules

$\mathrm{T}: \mathrm{mm}$

V: like I mean this, for the er for the sub- for the grammar subject itself, it's not for interpreter skills

B: $\mathrm{mmm}$

It is not clear whether either the Thai or the
Burmese participant understand the Vietnamese speaker's pronunciation of 'taught', but they make use backchannels to encourage her to continue (Kirkpatrick, 2007b).

A strategy of particular note is the use of speaker and participant paraphrase in order to ensure that a member of the group does eventually understand. In excerpt (14) below the Burmese participant rephrases the Singaporean's question to help the Laotian participant understand the original question.

14 L: every month in Lao, we hap (have) to test

B: weekly er monthly test

L: monthly test

B: monthly test yes [so

S: do they] do they write essays do they write essays do the pupils do the pupils write compositions?

$[\mathrm{L}$ remains silent so the Burmese participant intervenes]

B: can your students write an essay or paragraph writing, a composition?

L: yes I think they can because er as I a them to rai er the story they can write and some mistake

Later in this conversation the Singaporean and Burmese patiently paraphrase and repeat a question five times before the Laotian finally understands it (Kirkpatrick, 2007b). There is no raising of volume or pitch level, no indication or exasperation or irritability in the repeated rephrasings of the question. This suggests that the overarching goal in this type of lingua franca conversation is to ensure communication on the one hand, while preserving the face of the participants on the other. The focus on communication means that the participants consciously edit linguistic usage, such as local idioms of lexis, which might not be understood by the other participants. The focus on preserving face means that participants are prepared to adopt specific strategies, including repeated paraphrase, to ensure that no-one feels left out or gets left behind.

\section{Conclusion}

In this article a selection of linguistic features and communicative strategies which occur in the lingua franca use of English of nationals from ASEAN has been described. It must be stressed that the data set is small and the speakers, although they represent each of the ten countries of ASEAN, are all themselves English language teachers and this might also 
influence the ways that they speak and the communicative strategies that they adopt. The findings suggest, however, that the focus on communication that is evident in these interactions from the communicative strategies adopted by the speakers may have important implications for the English language curriculum and classroom, especially in contexts where English is being learned as a tool for lingua franca communication.

\section{Notes}

1 Readers will want to know what counts as a shared feature. Deterding and Kirkpatrick considered features that were used by speakers from at least four countries to be shared 'on the grounds that such features probably constitute part of an emergent regional English lingua franca' (2006: 393-4). This criterion is retained here.

2 For an illuminating discussion on the relative influence of British and American norms on past tense morphology in Asian Englishes, see Moody (2007).

\section{References}

Bolton, Kingsley. 2002. Hong Kong English: Autonomy and Creativity. Hong Kong: University Press

Dardjowidjojo, S. 2000. 'English teaching in Indonesia'. In The English Australia Journal, 18(1), pp. 22-30.

Deterding, D. \& A. Kirkpatrick. 2006. 'Emerging SouthEast Asian Englishes and intelligibility'. In World Englishes, 25(3/4), pp. 391-410.

Deterding, D., J. Wong, \& A. Kirkpatrick. 2008. 'The pronunciation of Hong Kong English'. In English World-wide, 29(2), forthcoming.

Fabricius, A. 2002. 'Ongoing change in modern RP: evidence for the disappearing stigma of t-glotalling'. In English World-wide, 23(1), pp. 115-36.

Gramley, S. \& K. M. Patzold. 2004. A Survey of Modern English Usage. London: Routledge.

Hickey, Raymond. 2004. Legacies of Colonial English. Cambridge: University Press.

Honna, N. 2006. 'English as a multicultural language and intercultural literacy'. Paper given at the International Association of World Englishes Conference, Chukyo University, December 7-9, 2006.

Hung, T. 2000. 'Towards a phonology of Hong Kong English'. In World Englishes, 19, pp. 337-56.

Ihalainen, O. 1994. 'The dialects of England since 1776'. In R. Burchfield, ed. Cambridge History of the English Language, Vol 5 English in Britain and Overseas. Origins and Development. Cambridge: University Press, pp. 197-274.

Jenkins, J. 2007. English as a Lingua Franca: Attitudes and Identity. Oxford: University Press.

Jenkins, J., M. Modiano \& B. Seidlhofer. 2001. 'Euro-
English'. In English Today, 17(4), pp. 13-21.

Kachru, B.B. 1985. 'Standards, codification and sociolinguistic realism: The English language in the Outer Circle'. In R. Quirk and H. Widdowson (eds.), English in the World. Cambridge: University Press, pp. 11-16.

Kirkpatrick, A. 2007a. World Englishes: Implications for International Communication and English Language Teaching. Cambridge: University Press.

—. 2007b. 'The communicative strategies of ASEAN speakers of English as a lingua franca'. In D. Prescott (ed.), English in Southeast Asia: Varieties, Literacies and Literatures. Newcastle. Cambridge Scholars Publishing, pp. 121-139.

Li, D.C.S. 2002. 'Cantonese-English code-switching research in Hong Kong: A survey of recent research'. In K. Bolton, ed. Hong Kong English: Autonomy and Creativity. Hong Kong: University Press, pp. 79-99.

Lieberman, E., J. B. Michel, J. Jackson, T. Tang \& M. A. Nowak. 2007. 'Quantifying the evolutionary dynamics of language'. Nature, 449(11), pp. 713-16.

McArthur, T. 2003. 'English as an Asian language'. In English Today, 19(2), pp. 19-23.

McLellan, J. \& M. David. 2007. 'A review of codeswitching research in Malaysia and Brunei Darussalam'. In D. Prescott, ed. English in Southeast Asia: Varieties, Literacies and Literatures. Newcastle. Cambridge Scholars Publishing, pp. 69-92.

Mesthrie, R. 2004. 'Synopsis: Morphological and syntactic variation in Africa and South and Southeast Asia'. In B. Kortmann, K. Burridge, R. Mesthrie, E.W. Schneider, \& C. Upton, eds. A Handbook of Varieties of English Volume 2. Berlin: Mouton de Gruyter, pp. 1132-41.

Meierkord, C. 2004. 'Syntactic variation in interactions across international Englishes'. In English Worldwide, 25(1), pp. 109-32.

Moody, A. 2007. 'Features of the syntax of Asian Englishes: Using the Asian ICE corpora to investigate norms'. In D. Prescott, ed. English in Southeast Asia: Varieties, Literacies and Literatures. Newcastle: Cambridge Scholars Publishing, pp. 47-68.

Okudaira, A. 1999. 'A study on international communication in regional organizations: the use of English as the "official" language of the Association of South East Asian Nations (ASEAN)'. In Asian Englishes, 2(1), pp. 91-107.

Prodromou, L. 2007a. 'Kettles of fish: Or, does unilateral idiomaticity exist?' In English Today, 23(3/4), pp. 34-39.

-. 2007b. 'Is ELF a variety of English?' In English Today, 23(2), pp. 47-53.

Rampton, M. B. H. 1990. 'Displacing the native speaker: Expertise, affiliation, and inheritance'. In ELTJ, 44, pp. 97-101.

Seidlhofer, B. 2004. 'Research perspectives in teaching English as a lingua franca'. In Annual Review of Applied Linguistics, 24, pp. 209-39.

Wells, J. C. 1982. Accents of English. Cambridge: University Press. 